\title{
Screening, identification, and colonization of fungal root endophytes against Dematophora necatrix: a ubiquitous pathogen of fruit trees
}

\author{
Joginder Pal ${ }^{1 *}$ (D, Satish K. Sharma', Sunita Devi², Ranjna Sharma², Hans Raj ${ }^{1}$, Monika Karn', Shalini Verma', \\ Pulla Reddy Vedukola ${ }^{1}$ and Anju Sharma ${ }^{2}$
}

\begin{abstract}
The goal of the present research was to ascertain the potential root endophytic fungi against Dematophora necatrix, Hartig, the causal pathogen of white root rot in apples; however, it has an expanded range of hosts across different fruit trees. Out of 36 endophytic fungi segregated from symptomless roots of apple, wheat, maize, marigold, cherry, and garlic plants, only 9 isolates showed inhibitory effect during preliminary screening and were further assayed under in vitro, pot, and field conditions against the white root rot pathogen/disease. Under in vitro conditions, maximum mycelial inhibition of $81.48 \%$ was obtained with the isolate Aspergillus aculeatus strain C2. Microscopic studies on interaction between fungal endophyte with hyphal tips of $D$. necatrix revealed various morphological abnormalities in the hyphae. In glasshouse conditions, seed treatment pursued by soil application with Crinipellis tabtim strain M8 isolate was highly effective and exhibited 93.55\% disease control. Similarly, under field conditions, the overall maximum disease control was exhibited by Crinipellis tabtim strain M8 (84.95\%). The most promising root endophytes that were identified rely on morphological and ITS sequence analysis. Root colonization assay was performed which revealed maximum endosphere and rhizosphere colonization with Crinipellis tabtim strain M8. Additionally, confocal microscopic illustrations of transverse sections of root cells tenanted by fungal endophytes as compared to untreated control suggested the persistence and establishment of endophytes in the endosphere of apple seedlings. These findings present the first report on colonization of apple roots by fungal root endophytes suggesting an alternative and sustainable approach for management of white root rot disease.
\end{abstract}

Keywords: White root rot, Apple, Dematophora necatrix, Fungal endophytes, Colonization, Sustainable management

\section{Background}

White root rot, caused by a soil-inhabiting fungus Dematophora necatrix Hartig, [Rosellinia necatrix (Hartig) Berl.], is ratified as one of the major distressing diseases of apples. In India, especially in Himachal Pradesh, this disease is continuously becoming a serious pitfall to apple cultivation. The state is recognized as the "apple

\footnotetext{
* Correspondence: jpal15889@gmail.com

${ }^{1}$ Department of Plant Pathology, Dr. Y.S. Parmar University of Horticulture and Forestry, Nauni, Solan, Himachal Pradesh 173230, India

Full list of author information is available at the end of the article
}

state" of the country. The disease is destructive both in nurseries and orchards therefore resulting in substantial yield and quality losses to apple orchardists in the state (Sharma et al. 2005a). The fungus has a very extensive host range and infects about 197 species belonging to 50 families including fruit plants, forest trees, vegetables, cereals, ornamentals, and other plants owing to high remunerative values (Ito and Nakamura 1984). The susceptibility of the host plants to this invading fungus is very extensive and has also been reported to induce root rot in a large number of temperate fruit crops for 
instance pear, plum, almond, peach, cherry, and olive plants and forest trees like Cedrus deodara and Quercus spp. (Sharma et al. 2009; Kulshrestha et al. 2014).

Endophytes that scrutinize the internal plant tissues are drawing the attention of agriculture scientists in view of the multifarious asset it confers to the host plant in terms of birthing bioactive secondary metabolites, stimulating growth, accelerating produce, inferring host to endure biotic and abiotic stresses, and imparting resistance against widespread diseases (Amin et al. 2013). Moreover, endophytes hold tremendous potential to be used as biocontrol agents (Santoyo et al. 2016), since these microorganisms exist in the interior host environment and perceive defense from environmental stresses, striving for lesser antagonism from other microorganisms, and have better access to nutrients (Dutta et al. 2014). The conceivable potential for intra-tissue colonization, and their intense association along with the host render endophytes more useful in biocontrol practice in comparison to rhizospheric microbes (Thomas and Reddy 2013; Thomas and Upreti 2014). Colonization of host plants by endophytic microorganisms leads to several cell wall alteration, for instance, deposition of callose-, cellulose-, pectin-, and phenol-related compounds provoking the development of a structural barricade at the point of attack by plant pathogens (Benhamou et al. 1998).

The goals of this study were to scrutinize the biocontrol potential of fungal root endophytes for the sustainable management of white root rot pathogen $(D$. necatrix) of apple and to study the establishment and root colonization behavior of selected fungal root endophytes in the endosphere of apple.

\section{Materials and methods}

\section{The fungal pathogen}

Dematophora necatrix, the causative agent of white root rot of apple, was isolated from diseased apple seedlings grown at Model Research Farm of Dr. Yashwant Singh Parmar University of Horticulture and Forestry Nauni Solan (H.P.), India, as per the procedure given by Sharma and Gupta (1996) and Sharma et al. (2005b). Pathogenicity of fungus was tested on 1-year-old apple seedlings grown in pots. The soil around the plants was removed gently to expose the fine root system, and 5-g wheat grain culture of $D$. necatrix was put in the soil surrounding roots and covered with the soil. A control was separately maintained in which all the operations were similar except the addition of the fungal culture. Treated pots were regularly watered and observed for the symptom appearance. Koch's postulates were proved by reisolating the fungus from diseased roots and compared with the original test fungus. The pathogen was grown on potato dextrose agar (PDA) plates incubated at $25 \pm 2{ }^{\circ} \mathrm{C}$ for 7 days. The cultures were stored in PDA slants at $4{ }^{\circ} \mathrm{C}$ for further use.

\section{Sampling}

Isolation of root endophytic fungi was executed from root sections of apple (Malus domestica) collected from 3 major apple-growing districts (Kullu, Shimla, and Kinnaur) of Himachal Pradesh. In addition, endophytic strains were also recovered from root sections of other plants including wheat (Triticum aestivum), maize (Zea mays), marigold (Tagetes erecta), cherry (Prunus avium), and garlic (Allium sativum), which were collected from Research Farm of our University. The plants were carefully uprooted with the help of a spade, placed in polypropylene bags, labeled, immediately brought to the laboratory, and processed within 24-48 h of collection.

\section{Isolation, purification, and maintenance of fungal endophytes}

The healthy root samples were collected, placed in sterile sealed plastic packets, immediately carried to the laboratory, and used within $24 \mathrm{~h}$. The plant samples were then cut into small fragments and washed beneath the tap water for the period of $10-15$ min to abolish adhesive soil particles. The separated plant roots were weighed to $1 \mathrm{~g}$. The weighed root sections were dipped in autoclaved distilled water and drained out eventually. The collected root specimens were then surfacedisinfected by soaking in $70 \%$ ethanol for $1 \mathrm{~min}$ and with $4 \%$ sodium hypochlorite $(\mathrm{NaOCl})$ for $5 \mathrm{~min}$ and later on treated with $70 \%$ ethanol for $30 \mathrm{~s}$ pursued by flushing 5 times in distilled water. The disinfected sections were blot-dried employing sterilized filter paper and were macerated and impregnated in $1 \mathrm{ml}$ of distilled water utilizing sterilized pestle and mortar. The macerated root sections were sequentially diluted up to $10^{-5}$ dilutions. $0.1 \mathrm{ml}$ of specific dilution of the particular specimens was splashed in Petri dishes remarkably marked from $10^{-1}$ to $10^{-5}$ containing PDA medium and scattered with the spreader. The plating was replicated thrice for respective dilution. The Petri dishes were incubated at $28 \pm 2{ }^{\circ} \mathrm{C}$ for 14 days. The fungal root endophytes thus obtained were revived and stored for preservation, using PDA slants (Sharma and Roy 2015). Fungal root endophytes isolated from apple were designated as Ap, S2, K1, and K3. Other root endophytes such as M1 and M8, C1, G, and C2 were isolated from other crops viz., marigold, cherry, wheat, and garlic, respectively.

\section{Morphological and molecular characterizations of fungal endophytes}

The root endophytes were identified and characterized depending upon distinctive morphological and cultural 
features as per the identification keys illustrated by earlier researchers (Mathur and Olga 2003; Samson et al. 2011; Hanafusa et al. 2016). The mycelium of endophytes was stained for $10 \mathrm{~min}$, using lactophenol cotton blue. Thereafter, stained microscopic slides were visualized at $\times 40$ magnification using compound microscope.

\section{Isolation of fungal endophytes genomic DNA}

The genomic DNA of fungal endophytes was isolated by practicing cetyl trimethyl ammonium bromide (CTAB; Sigma Chemical., St. Louis, USA) method (Murry and Thompson 1980) practicing little modifications. For DNA isolation, fungal tissues were harvested utilizing 7day-old culture of each isolate grown in potato dextrose broth (PDB). After incubation, mycelial mat of each fungus was percolated through sterile filter paper and thereafter, mended to powdered form in liquid nitrogen. About $1 \mathrm{~g}$ of ground mycelium was collected into a microcentrifuge tube containing $1 \mathrm{ml}$ of pre-warm $\left(65^{\circ} \mathrm{C}\right)$ DNA extraction buffer. Subsequently, mixed by exercising gentle rotation (DNA extraction buffer: 100 $\mathrm{mM}$ Tris- $\mathrm{HCl}$ (pH 8.0), $20 \mathrm{Mm}$ EDTA (pH 8.0), $1.4 \mathrm{M}$ $\mathrm{NaCl}, 2 \%(\mathrm{w} / \mathrm{v})$, CTAB 0. $2 \%(\mathrm{v} / \mathrm{v}), \beta$-Mercaptoethanol). The sample was incubated at $65^{\circ} \mathrm{C}$ for $1 \mathrm{~h}$, and it was mixed twice by introverting tube. One milliliter chloroform:isoamyl alcohol was added $(24: 1, \mathrm{v} / \mathrm{v})$ and mixed by inversion. Spinning was done at $12,000 \mathrm{rpm}$ for approximately $20 \mathrm{~min}$ at room temperature. Aqueous phase was pipetted out gently without perturbing the interphase to a new tube. The $2 / 3$ rd volume of isopropanol was added and mixed by gentle inversion. DNA pellet was spinned down by centrifugation at $12,000 \mathrm{rpm}$ for $10 \mathrm{~min}$ at $4{ }^{\circ} \mathrm{C}$. It was washed twice using $70 \%$ ethanol and again spinned at $10,000 \mathrm{rpm}$ for $5-10 \mathrm{~min}$ at $4{ }^{\circ} \mathrm{C}$. Pellet was dried and dissolved in 50-100 $\mu \mathrm{l}$ TE buffer ( $\mathrm{pH}$ 8.0) depending upon the yield of DNA. Isolated DNA was inspected on agarose (0.8\%).

\section{Amplification of the internal transcribed spacer (ITS)}

To understand the variation among root endophytic isolates at sequence level, a region of the nuclear rDNA gene encoding for the ITS regions was amplified from the genomic DNA by PCR machine using the primer ITS $1(1: 100 \mathrm{pmol} / \mu \mathrm{l})$ and ITS $4(4: 100 \mathrm{pmol} / \mu \mathrm{l})$. PCR was performed in $25 \mu \mathrm{l}$ reaction volume containing $0.5 \mu \mathrm{l}$ Taq DNA polymerase, $2.5 \mu \mathrm{l}$ Taq buffer A, $1.0 \mu \mathrm{l}$ dNTPs mixture (GeNei, Bangalore, India), $1.0 \mu \mathrm{l}$ ITS 1 primer, $1.0 \mu \mathrm{l}$ ITS 4 primer (Semmelweisstr, Bavaria, Germany), $1.5 \mu \mathrm{l}$ genomic DNA, and $17.5 \mu \mathrm{l}$ molecular grade water. The PCR amplification events were governed in a thermal cycler with a total of 45 cycles. Each cycle consisted of initial denaturation at $94{ }^{\circ} \mathrm{C}$ for $2 \mathrm{~min}$ and $30 \mathrm{~s}$, denaturation at $94{ }^{\circ} \mathrm{C}$ for $30 \mathrm{~s}$, annealing at $58^{\circ} \mathrm{C}$ for $30 \mathrm{~s}$, extension at $72{ }^{\circ} \mathrm{C}$ for $1.5 \mathrm{~min}$, final extension at $72^{\circ} \mathrm{C}$ for $5 \mathrm{~min}$.

\section{Electrophoresis of amplified DNA}

The electrophoresis of the amplified DNA was performed over agarose gel (2\%) containing ethidium bromide $(0.5 \mathrm{mg} / \mathrm{ml})$. To each PCR amplified sample, $4 \mu \mathrm{l}$ of 6X loading dye was added. One hundred-base pair DNA ladder marker (GeNei Bangalore, India) was used as standard and the gel was run at $110 \mathrm{~V}$. The amplified DNA was inspected under the UV trans-illuminator and the image was regulated through gel documentation system (Syngene).

\section{DNA sequencing and sequence analysis}

For DNA sequence analysis, purified and amplified DNA products of selected fungal endophytic isolates were outsourced to the National Centre for Microbial Resource (NCCS), Pune, India, under refrigerated conditions using gel packs and thermocol box. Sequenced data so procured was assessed with the help of tools like BLAST (Basic Local Alignment Search Tool) (www.ncbi.nlm.nih. gov) for homology. All the sequences used for phylogenetic analysis were analyzed by MEGA 6.0 software using neighbor-joining method.

\section{Evaluation of root endophytes against white root rot of apple} In vitro antagonism assay of fungal root endophytes

Nine promising fungal endophytic isolates proved efficient after initial screenings were evaluated further under in vitro conditions by following dual culture method (Coskuntuna and Ozer 2008). Seven-day-old culture disks (4-mm diameter) of each of the antagonist and the pathogen were taken from the margin of actively growing culture with the help of sterilized cork borer and transferred aseptically to solidified PDA in Petri dishes $(90 \mathrm{~mm})$ by placing them on the same plate opposite to each other $(6 \mathrm{~cm}$ apart from each other) at an equal distance of $1 \mathrm{~cm}$ from the edge of the plate. The Petri dish incorporated only with culture disk of the pathogen treated as control. Each treatment was replicated three times. Petri dishes were incubated at $25 \pm$ $1{ }^{\circ} \mathrm{C}$ for 7 days when the test pathogen in the control Petri dish grew fully, i.e., covering $90 \mathrm{~mm}$ culture medium. The colony interactions were assayed as percent inhibition of the radial growth by the following formula (Fokkema 1976): $R_{1}-R_{2} / R_{1} \times 100$, where, $R_{1}$ denotes diameter of the radial growth of the pathogen towards opposite side and $R_{2}$ denotes the radial growth of the pathogen towards the opponent antagonist. 


\section{Mycelial growth test}

Selected fungal root endophytic isolates that showed a significant inhibition of $D$. necatrix under dual culture assay were further subjected to view the mechanism of action under compound microscopy (Yurnaliza et al. 2014). The changes in the mycelial growth/hyphal tip of D. necatrix at the interaction zone treated with selected root endophytes were observed under $\times 40$ magnification and compared with control.

\section{Antagonisms of selected root endophytes against white root rot under glasshouse and field conditions}

On the basis of in vitro antagonistic potential, the endophytic microbes were further examined for their disease control potential in glasshouse and field situations. Glasshouse experiment (seed dip treatment and soil application) was conducted at UHF, Nauni Solan, and field trial was conducted at Regional Horticultural Research and Training Station, Sharbo Reckong Peo, Kinnaur, situated at an elevation of $2,121.4 \mathrm{~m}$ above mean sea level.

\section{Evaluation under glasshouse conditions}

Stratified apple seeds were soaked or treated in respective fungal $\left(2 \times 10^{6} \mathrm{cfu} / \mathrm{ml}\right)$ endophytic suspensions (PDB) and incubated in shaking incubator for 7 days. The treated seeds were dried in a sterile stream of air at room temperature for $1 \mathrm{~h}$ before planting in the pots. The endophytic fungal population $\left(2 \times 10^{6} \mathrm{cfu} / \mathrm{ml}\right)$ was adjusted with the aid of a hemocytometer. Four seeds of apple were sown at depth of $2 \mathrm{~cm}$ in each small sized plastic pot $(10 \mathrm{~cm}$ high and $8 \mathrm{~cm}$ internal diameter) containing sterilized potting mixture consisting of soil, sand, and cow dung at 2:1:1. The potting mixture used was sterilized by tyndallysing the soil in polybags for $1 /$ 2 an hour for three successive days at $100{ }^{\circ} \mathrm{C}$ temperature. The potted plants at 4-5-cm height were again drenched two times $(50 \mathrm{ml} \times 2)$ at weekly intervals with $100 \mathrm{ml}$ of fully grown endophyte suspension around the root zone. Subsequently, 7 days after last application, each treatment was challenged inoculated by adding the culture of D. necatrix grown on wheat grains at $0.1 \%(\mathrm{w} / \mathrm{w})$. For control, no fungal endophytic cultures was used (seeds were dipped in non-chlorinated water). All treatment was replicated thrice. The temperature in the greenhouse ranged from 15 to $25^{\circ} \mathrm{C}$ with $12 \mathrm{~h}$ photoperiod. Treated pots were watered regularly and data on incidence and percent disease control (PDC) were recorded and calculated at 15, 30, and 45 days of pathogen inoculation following Sharma and Gupta (1997):

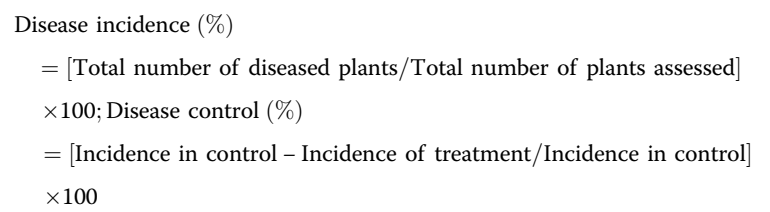

\section{Evaluation under field conditions}

Stratified apple seeds were soaked or treated in respective fungal $\left(2 \times 10^{6} \mathrm{cfu} / \mathrm{ml}\right)$ endophytic suspensions (PDB) and shaker incubated for 7 days for $1 / 2$ an hour and shade dried for $1 \mathrm{~h}$ before transplanting in the field. After 2 months of transplantation, the potted plants at 10-15-cm height were again drenched with [2 times (50 $\mathrm{ml} \times 2)$ at weekly intervals] $100 \mathrm{ml}$ endophyte suspension around the root zone. After 7 days of last application, each treatment was challenged inoculated by adding culture of $D$. necatrix grown on wheat grains at $0.1 \%(\mathrm{w} / \mathrm{w})$. For control, no fungal endophytic cultures was used (seeds were dipped in non-chlorinated water). The treatment was replicated 3 times. Row-to-row and plant-to-plant distance were maintained following standard agronomical guidelines developed for apple. The treated plants in the field were watered regularly, and data on incidence and PDC were recorded as described above.

\section{Establishment and root colonization assay of selected fungal root endophytes}

Out of the tested endophytes, the six most effective root endophytes which proved significant in controlling root rot both under glasshouse and field situations were further screened for their establishment and root colonization under confocal laser scanning microscopy (CLSM). Apple seedling assumes hardy and woody nature under field conditions; therefore, to study colonization and for ease in preparation of samples for confocal microscopy, root specimens were collected from glasshouse experiment. Treated plants were permitted to develop for 3 weeks and watered through sterile distilled water once in 2 days. After 21 days of seed treatment, plants were uprooted, rinsed multiple times with sterile water, and preserved for visualization under microscopy.

\section{Root colonization assay of selected root endophytes}

The ability of selected root endophytes to colonize roots of apple seedlings was enumerated at dilution $10^{-2}$ by isolating the total count (cfu/g of root samples) on PDA after 7 and 21 days of application of endophytic suspension by serial dilution and plate count technique (Agarwal and Hasija 1986). 


\section{Microscopic elucidation of colonized and established root endophytes}

To analyze the potentiality of the efficient root endophytes to colonize the apple roots, CLSM were used [Advanced Materials Research Center (AMRC), Indian Institute of Technology, Mandi (H.P.), India]. The roots were uprooted and surface-sterilized with $\mathrm{NaOCl}(1 \%)$ for $3 \mathrm{~min}$, soaked two times in distilled water, placed on pre-sterile paper in a laminar air flow chamber, and stored in ethanol $(70 \%)$. Thin transverse sections were prepared from fresh root tissue using sterilized dissecting blade. Thereafter, root sections were disposed on microscopic slide and immersed with 2-3 droplets of calcofluor white stain (catalog \#18909, Sigma Aldrich) and stained for 10-20 min, following the manufacturer's protocol and scanned with a Leica TCS SP5 CLSM at excitation $(405 \mathrm{~nm})$ with an argon laser $(17 \%)$ and 488 $\mathrm{nm}$ with a green helium laser $(25 \%)$, the emission ranges were $418-452 \mathrm{~nm}$ and $603-689 \mathrm{~nm}$, pinhole $[\mathrm{Au}]=1.0$ airy, objective lens $=\times 63$ oil immersion, and frame average $=3$ times. Confocal imaging of different endophytic suspensions treated root sections were compared with control root sections images. Two-dimensional illustrations were prepared and processed via LSM browser, MS-Power Point and Adobe Photoshop 7.0 (Thomas and Reddy 2013).

\section{Statistical analysis}

The data gathered from laboratory and field experiments were dispensed to appropriate statistical analysis using standard procedures and as specified by Gomez and Gomez (1984). Critical differences (CD) among the treatments in various experiments at 5\% level were also calculated to ascertain the least significant differences (LSD).

\section{Results and discussion}

\section{Pathogenic potential of $D$. necatrix}

Pathogenicity test revealed that symptoms of disease appeared after 13 days in inoculated plants, which died completely 45 days of pathogen inoculation. The Koch's postulates were proved by reisolating the same fungus from the diseased roots and were confirmed to be the same fungus ( $D$. necatrix) by comparing with original culture.
Isolation and quantitative estimation of fungal root endophytes

A total of 36 fungal endophytes were isolated from root sections of apple and other plants collected from three major apple-growing districts (Kullu, Shimla, and Kinnaur) and locally available plants of our university. In apples, endophytic fungal strains were found predominant in district Shimla (6 no. isolates), followed by Kullu (4 no. isolates). However, least (3 no. isolates) occurrence was registered in district Kinnaur. In the case of other plants, maximum root endophytes (10 no. isolates) were recorded in marigold followed by maize (4 no. isolates). However, three fungal endophytes were obtained each from garlic, wheat, and cherry. The predominant fungal endophytic colonies were selected and purified, and the pure culture of each isolate was maintained at $4{ }^{\circ} \mathrm{C}$ on PDA for further studies. The variation in microbial population may be attributed to climatic conditions of the location, age of plant, variety/cultivar type, sampling time, and physicochemical properties of soil.

\section{Morphological and cultural characterization of fungal root endophytes}

Based on preliminary screening, the 9 most promising fungal root endophytes were selected and subjected to morphological and cultural characterization. Based on morphological, and cultural characteristics of the representative isolates, and as per the identification keys given by earlier researchers to the different fungal genera, the isolates M1, G, S2, K1, and K3 were identified as Fusarium sp. (Mathur and Olga 2003), C1, and C2 as Aspergillus sp. (Samson et al. 2011), whereas, Ap and M8 were identified as Penicillium sp. and Schizophyllum sp., respectively (Hanafusa et al. 2016).

\section{ITS sequencing \\ Phylogenetic analysis and amplification of fungal genomic DNA}

Fungal genomic DNA of 6 promising fungal root endophytes was isolated by conventional method and quantified via agarose gel electrophoresis (1.0\% agarose) under standard conditions. The ITS sequence analysis of six selected isolates was assessed by using universal primers. The ITS amplified products obtained with ITS primers

Table 1 Identification of fungal root endophytes isolated from apple and other plants

\begin{tabular}{|c|c|c|c|c|c|}
\hline Isolate & Identified as & Closest neighbor & Host root sample & GenBank accession no. & Maximum identity (\%) \\
\hline M1 & Fusarium equiseti & Fusarium equiseti NRRL 26419 & Marigold & MK359033 & 99 \\
\hline Ap & Talaromyces aculeatus & Talaromyces aculeatus strain NRRL2129 & Apple & MK359034 & 98 \\
\hline G & Neocosmospora perseae & Neocosmospora perseae & Wheat & MK359035 & 98 \\
\hline $\mathrm{C} 2$ & Aspergillus aculeatus & Aspergillus aculeatus CBS 172.66 & Garlic & MK359036 & 100 \\
\hline M8 & Crinipellis tabtim & Crinipellis tabtim CMU JFK129 (type) & Marigold & MK359037 & 86 \\
\hline K3 & Fusarium circinatum & Fusarium circinatum CBS 405.97 & Apple & MK359038 & 98 \\
\hline
\end{tabular}




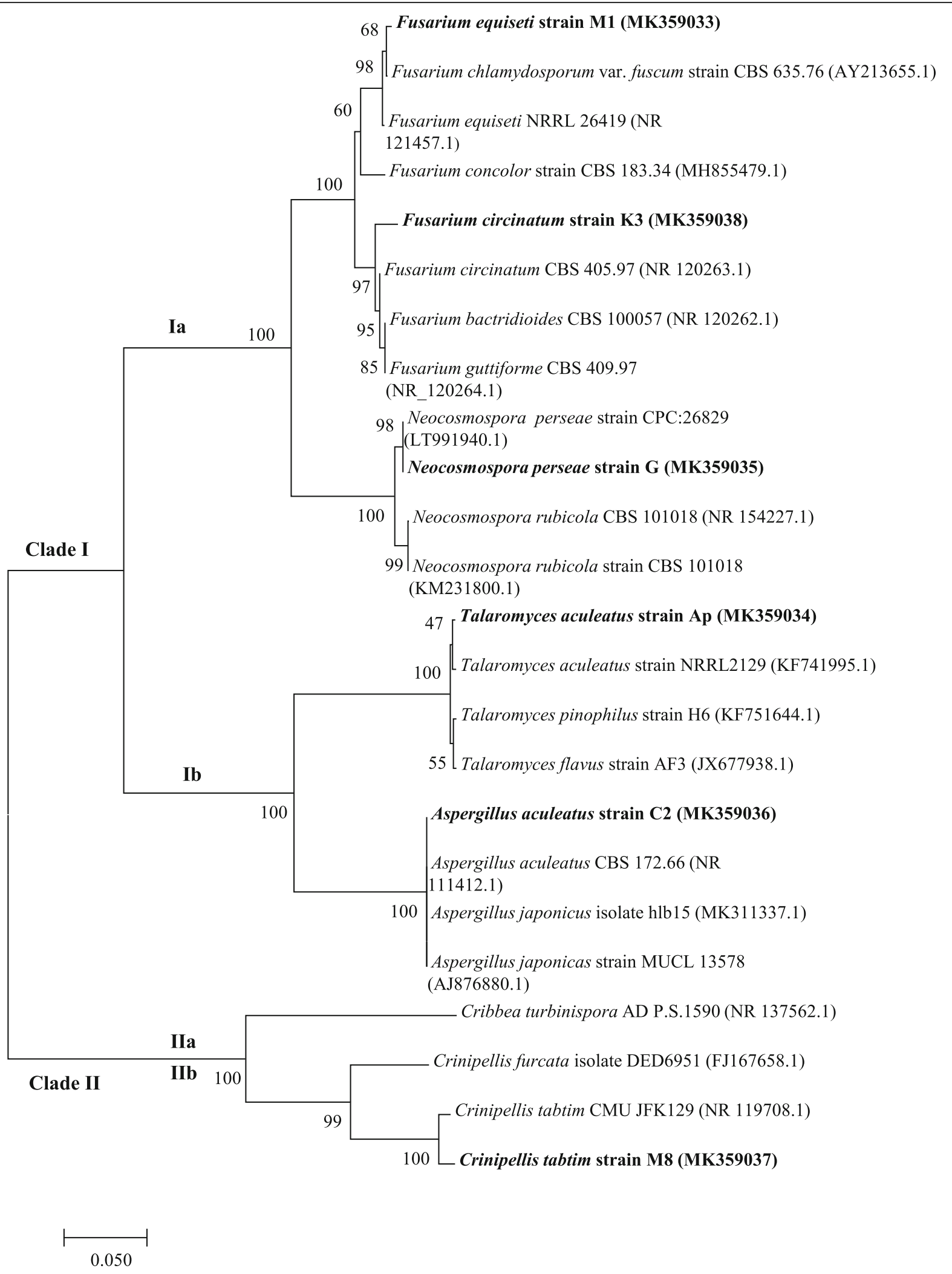

Fig. 1 Phylogenetic tree based on the ITS sequences drawn using neighbor-joining method showing relationship between the 6 isolates of fungal root endophytes and similar other sequences deposited in the NCBI GenBank, USA. Evolutionary analyses were operated in MEGA 6.0 
(ITS1 and ITS4) were used for sequencing. All the sequences used for phylogenetic analysis were analyzed by MEGA 6.0 software using neighbor-joining method.

\section{Sequence analysis}

Phylogenetic studies confirmed the affiliation of the 6 representative fungal root endophytes isolated from different crops. The ITS gene amplicons obtained from the fungal root endophytes showed homology to the already submitted sequences of different fungal isolates available in National Centre for Biotechnology Information (NCBI) databases. These sequences were further submitted to GenBank (NCBI). The accession numbers of submitted sequences and their homology with
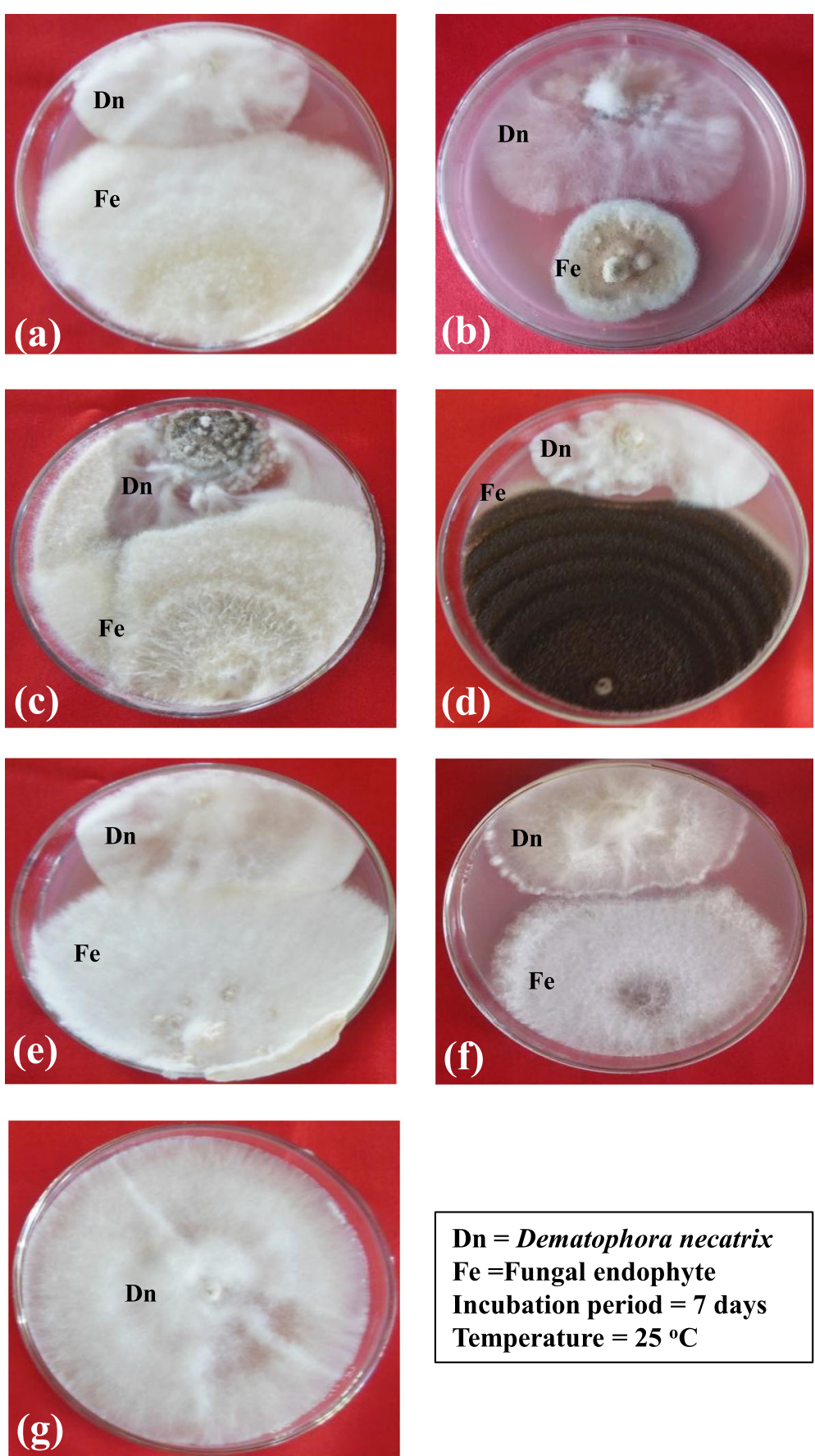

$$
\begin{aligned}
& \text { Dn = Dematophora necatrix } \\
& \text { Fe =Fungal endophyte } \\
& \text { Incubation period }=7 \text { days } \\
& \text { Temperature }=25^{\circ} \mathrm{C}
\end{aligned}
$$

Fig. 2 In vitro activity of fungal endophytes [a Fusarium equiseti strain M1, b Talaromyces aculeatus strain Ap, c Neocosmospora perseae strain G, d Aspergillus aculeatus strain C2, e Crinipellis tabtim strain M8, $\mathbf{f}$ Fusarium circinatum strain K3, and $\mathbf{g}$ control] against D. necatrix, causing white root rot of apple 
sequences present in NCBI database are given in Table 1. The phylogenetic relationship showed 2 major clads viz., (i) clad one consisted of Crinipellis isolates. However, clad II further divided in to 2 subgroups-clad II(a) contained Fusarium and Neocosmospora genera, whereas clad II(b) comprised of Talaromyces and Aspergillus (Fig. 1). The 6 endophytic fungal genera showed relationship with similar other sequences deposited in the NCBI GenBank with $50 \%$ bootstrap value.

\section{In vitro antagonism assay}

Out of total 36 fungal root endophytes isolated, 9 were evaluated for antifungal activity by dual culture technique (Fig. 2). The data depicted in Table 2 indicated that all the root endophytes tested inhibited the mycelial growth of $D$. necatrix, but the degree of inhibition varied with endophyte. The maximum inhibition of $81.48 \%$ was recorded in Aspergillus aculeatus strain C2, followed by Aspergillus sp. (C1) (75.19\%). The isolate Fusarium sp. (S2) was least efficient in inhibiting the mycelial growth of the pathogen (53.33\%). The endophytes which showed significant inhibition of $D$. necatrix were further investigated under compound microscope in order to view the type of interaction at zone (Fig. 3). The various morphological changes and abnormalities of hyphal tips of $D$. necatrix resulted due to interaction with different fungal root endophytes were presented in Table 2. Haiyan et al. (2005) noticed that, out of 130 endophytic fungi segregated from Chinese medicinal plants, only $30 \%$ displayed antagonistic behavior. Likewise, Kim et al. (2007) also revealed that endophytic fungi secluded from vegetable crops displayed in vitro antagonism against Pythium ultimum, Phytophthora infestans, P. capsici, and Talaromyces flavus were reported as antagonists for controlling Verticillium wilt in cotton, eggplant, potato, and tomato (Naraghi et al. 2010). In the interaction zone, various morphological changes and abnormalities of hyphal tips of $D$. necatrix were observed with different fungal endophytes (Table 2). Endophytic fungi have been perceived to liberate diverse plant hormones and secondary metabolites that can diminish the potential consequences of pathogenic attack (Gao et al. 2010; Aharwal et al. 2016). Furthermore, antimicrobial metabolites sequestered from endophytes pertain to different structural classes, including alkaloids, steroids, terpenoids, peptides, phenols, flavonoids, and quinones (Shentu et al. 2014). Yurnaliza et al. (2014) while working with Ganoderma boninense (a main pathogen in oil palm plantation) observed that the fungal endophytes attached themselves to the hyphae of pathogen at the interaction zone thereby causing hyphal abnormalities.

\section{Screening and root colonization assay under glasshouse and field conditions}

On the basis of in vitro antagonism, most promising endophytic microbes (9 isolates proved efficient under preliminary screening) were further screened for their diseases control potential under glasshouse, and field conditions.

\section{Biocontrol activity of fungal root endophytes in glasshouse conditions}

Data depicted in Table 3 revealed that seed treatment with Crinipellis tabtim strain M8 was highly effective exhibiting minimum disease incidence, i.e., $5.55 \%$ up to 45 days of pathogen inoculation, followed by Fusarium equiseti strain M1 (9.26\%), and Talaromyces aculeatus strain Ap (14.81\%). It was further observed that up to

Table $\mathbf{2}$ In vitro antagonistic activity of fungal root endophytes against Dematophora necatrix

\begin{tabular}{|c|c|c|c|}
\hline Isolate & Mycelial growth (mm) & Mycelial growth inhibition (\%) & Changes in mycelial growth at interaction zone \\
\hline Fusarium equiseti strain $\mathrm{M} 1$ & 27.33 & $69.63(56.54)$ & $\begin{array}{l}\text { Mycoparasitism by endophytes on pathogen } \\
\text { hyphae by coiling around them }\end{array}$ \\
\hline Aspergillus sp. (C1) & 22.33 & $75.19(60.11)$ & $\begin{array}{l}\text { Penetration and increased swelling on pear-shaped } \\
\text { hyphae of pathogen }\end{array}$ \\
\hline Talaromyces aculeatus strain Ap & 39.33 & $56.30(48.60)$ & Penetration, bulging, and lysis of pathogen hyphae \\
\hline Neocosmospora perseae strain G & 30.67 & $65.93(54.27)$ & Bulging and abnormalities on pathogen hyphae \\
\hline Aspergillus aculeatus strain C2 & 16.67 & $81.48(64.49)$ & Distortion and malformation on pathogen hyphae \\
\hline Crinipellis tabtim strain M8 & 32.33 & $64.07(53.15)$ & $\begin{array}{l}\text { Thickening on pear-shaped swelling due to } \\
\text { mycoparasitic interaction }\end{array}$ \\
\hline Fusarium sp. (S2) & 42.00 & $53.33(46.89)$ & $\begin{array}{l}\text { Deformation and distortion of hyphae followed by } \\
\text { decreased length between septa of hyphae }\end{array}$ \\
\hline Fusarium sp. (K1) & 33.67 & $62.59(52.27)$ & $\begin{array}{l}\text { Encircling, penetration, and abnormalities on } \\
\text { pathogen hyphae }\end{array}$ \\
\hline Fusarium circinatum strain $\mathrm{K} 3$ & 36.67 & $59.26(50.32)$ & $\begin{array}{l}\text { Browning, thickening, and swelling on hyphae } \\
\text { of pathogen }\end{array}$ \\
\hline Control & 90.00 & $0.00(0.00)$ & \\
\hline $\mathrm{CD}_{0.05}$ & & 1.21 & \\
\hline
\end{tabular}

Figures in parentheses are arc sine transformed values 

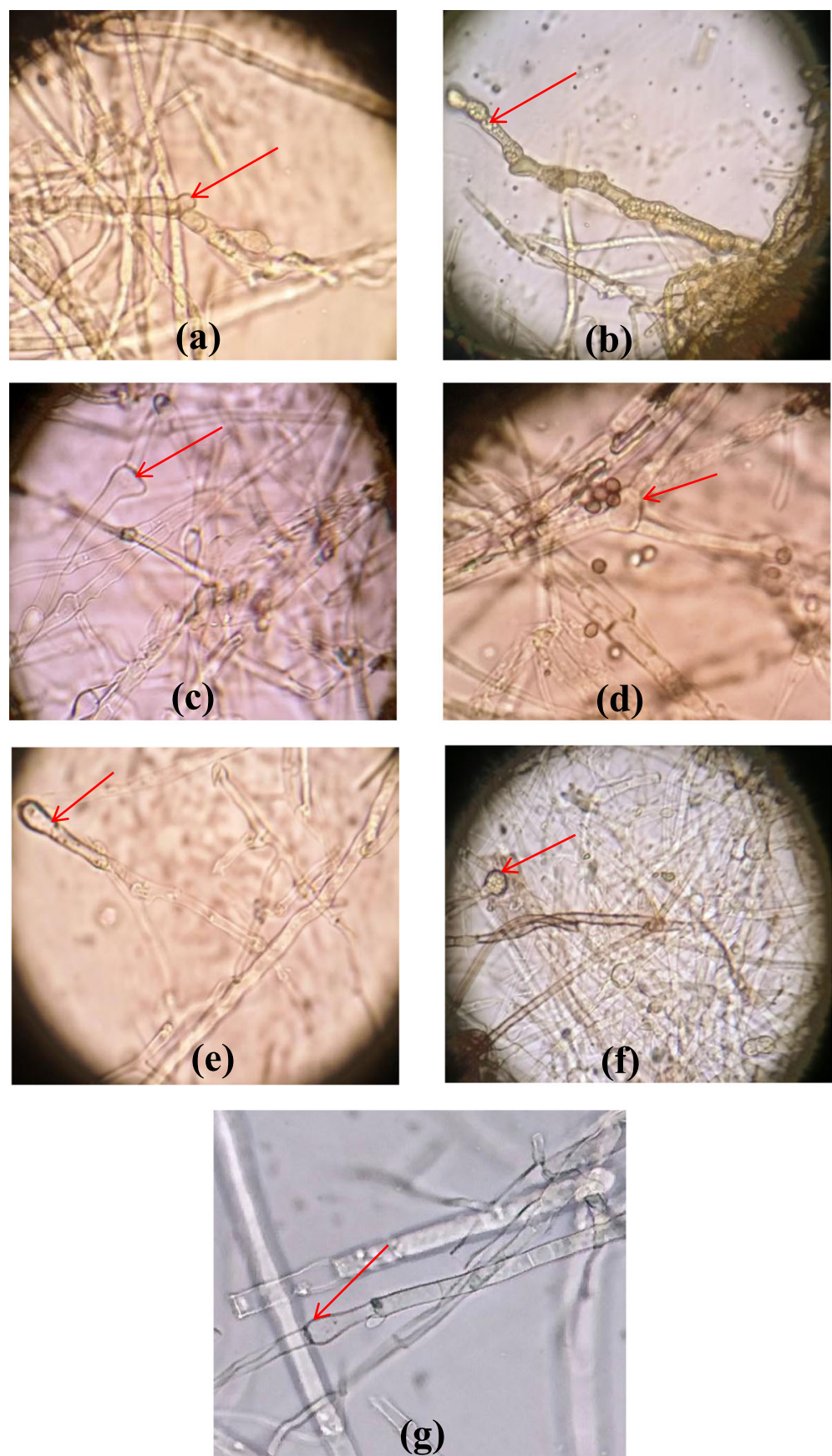

Fig. 3 Changes in the mycelial growth of D. necatrix after interaction with fungal root endophytes [a Fusarium equiseti strain M1, b Talaromyces aculeatus strain Ap, c Neocosmospora perseae strain G, d Aspergillus aculeatus strain C2, e Crinipellis tabtim strain M8, f Fusarium circinatum strain $\mathrm{K} 3$, and $\mathbf{g}$ control] isolated from apple and other crops

15 days of pathogen inoculation, there was no disease incidence in treatment $F$. equiseti strain M1, T. aculeatus strain Ap, C. tabtim strain M8, and F. circinatum strain K3. Disease appeared after 30 days of inoculation, and further increased at slower rate up to 45 days in comparison to control. Further, it was also observed that seed treatment with root endophytes resulted in prolonging the incubation period. The overall maximum percent disease control was exhibited by C. tabtim strain M8 isolate (93.55\%), followed by F. equiseti strain M1 (89.25\%). However, Aspergillus sp. (C1) was least effective with 58.07\% disease control. Yuan et al. (2017) showed the efficiency of 4 endophytic fungi, namely Penicillium simplicissimum, Leptosphaeria sp., Talaromyces flavus, and Acremonium 
Table 3 Effect of seed dip treatment with fungal root endophytes on white root rot of apple in glasshouse conditions

\begin{tabular}{|c|c|c|c|c|c|}
\hline \multirow[t]{2}{*}{ Isolate } & \multicolumn{3}{|c|}{ Disease incidence (\%) after pathogen inoculation } & \multirow[t]{2}{*}{ Mean (\%) } & \multirow{2}{*}{$\begin{array}{l}\text { Percent } \\
\text { disease } \\
\text { Control } \\
\text { (\%) }\end{array}$} \\
\hline & 15 & 30 & 45 & & \\
\hline Fusarium equiseti strain M1 & $0.00(0.00)$ & $8.33(16.77)$ & $19.44(26.05)$ & $9.26(14.27)$ & 89.25 \\
\hline Aspergillus sp. (C1) & $16.66(24.08)$ & $38.88(38.54)$ & $52.78(46.58)$ & $36.11(36.39)$ & 58.07 \\
\hline Talaromyces aculeatus strain Ap & $0.00(0.00)$ & $16.66(24.08)$ & $27.78(31.74)$ & $14.81(18.61)$ & 82.80 \\
\hline Neocosmospora perseae strain G & $8.33(16.77)$ & $25.00(29.99)$ & $36.11(36.89)$ & $23.15(27.88)$ & 73.12 \\
\hline Aspergillus aculeatus strain C2 & $8.33(16.77)$ & $25.00(29.99)$ & $44.44(41.78)$ & $25.92(29.51)$ & 69.90 \\
\hline Crinipellis tabtim strain M8 & $0.00(0.00)$ & $0.00(0.00)$ & $16.66(24.08)$ & $5.55(8.02)$ & 93.55 \\
\hline Fusarium sp. (S2) & $16.66(24.08)$ & $33.33(35.25)$ & $50.00(44.98)$ & $33.33(34.77)$ & 61.29 \\
\hline Fusarium sp. (K1) & $8.33(16.77)$ & $27.78(31.74)$ & $52.78(46.58)$ & $29.63(31.69)$ & 65.59 \\
\hline Fusarium circinatum strain $\mathrm{K} 3$ & $0.00(0.00)$ & $16.66(24.08)$ & $38.88(38.54)$ & $18.51(20.87)$ & 78.50 \\
\hline Control & $58.33(49.82)$ & $100.00(89.39)$ & $100.00(89.39)$ & $86.11(76.20)$ & 0.00 \\
\hline Mean & $11.66(14.83)$ & $29.16(31.98)$ & $43.89(42.66)$ & & \\
\hline $\mathrm{CD}_{0.05}$ & \multicolumn{5}{|c|}{ Isolate $(I s)=1.73$, Interval $(I)=0.95$, Isolate $(I s) \times$ Interval $(I)=3.00$} \\
\hline
\end{tabular}

sp. secluded from cotton roots, which significantly controlled Verticillium wilt of cotton. In greenhouse conditions, all treatments significantly decreased disease incidence and disease index and the potentiality ranging from 26 (CEF-642) to 67\% (CEF-818) after 25 days of inoculation.

\section{Biocontrol activity of selected fungal root endophytes under field conditions}

Most root endophytes screened against white root rot under glasshouse conditions were further evaluated under field conditions at the Regional Horticultural Research and Training Station Sharbo, Kinnaur (H.P.). The data embedded in Table 4 revealed that all the fungal endophytes treatments were effective in checking the white root rot of apple in comparison to control. The incidence of disease was recorded minimum (12.96\%) upon seed treatment with C. tabtim strain M8 suspension, followed by $F$. equiseti strain M1 (15.74\%), and T. aculeatus strain Ap (18.51\%). Further, no noticeable symptoms were recorded in these treatments up to 15 days of pathogen inoculation. Disease appeared after 30 days of inoculation. It was also noticed that seed treatment with root endophytes resulted in prolonging the incubation period. The overall maximum percent disease control was exhibited by C. tabtim strain M8 (84.95\%). F. equiseti strain M1 was the next best in order, and provided $81.72 \%$, followed by T. aculeatus strain Ap with 78.50\% PDC. However, Aspergillus sp. (C1) as in the glasshouse experiment

Table 4 Effect of seed treatment with fungal root endophytes on white root rot of apple under field conditions

\begin{tabular}{|c|c|c|c|c|c|}
\hline \multirow[t]{2}{*}{ Isolate } & \multicolumn{3}{|c|}{ Disease incidence (\%) after pathogen inoculation } & \multirow[t]{2}{*}{ Mean (\%) } & \multirow{2}{*}{$\begin{array}{l}\text { Percent } \\
\text { disease } \\
\text { Control } \\
(\%)\end{array}$} \\
\hline & 15 & 30 & 45 & & \\
\hline Fusarium equiseti strain M1 & $0.00(0.00)$ & $16.66(24.08)$ & $30.55(33.49)$ & $15.74(19.19)$ & 81.72 \\
\hline Aspergillus sp. (C1) & $19.44(26.05)$ & $41.66(40.18)$ & $58.33(49.77)$ & $39.81(38.67)$ & 53.77 \\
\hline Talaromyces aculeatus strain Ap & $0.00(0.00)$ & $16.66(24.08)$ & $38.88(38.54)$ & $18.51(20.87)$ & 78.50 \\
\hline Neocosmospora perseae strain G & $8.33(16.77)$ & $27.78(31.74)$ & $52.78(46.58)$ & $29.63(31.69)$ & 65.59 \\
\hline Aspergillus aculeatus strain C2 & $13.88(21.64)$ & $33.33(35.25)$ & $52.78(46.58)$ & $33.33(34.49)$ & 61.29 \\
\hline Crinipellis tabtim strain M8 & $0.00(0.00)$ & $13.88(21.64)$ & $25.00(29.99)$ & $12.96(17.21)$ & 84.95 \\
\hline Fusarium sp. (S2) & $16.66(24.08)$ & $41.66(40.18)$ & $55.55(48.18)$ & $37.96(37.48)$ & 55.92 \\
\hline Fusarium sp. (K1) & $16.66(24.08)$ & $30.55(33.49)$ & $50.00(44.98)$ & $32.40(34.19)$ & 62.37 \\
\hline Fusarium circinatum strain K3 & $8.33(16.77)$ & $16.66(24.08)$ & $41.66(40.18)$ & $22.22(27.01)$ & 74.20 \\
\hline Control & $58.33(49.82)$ & $100.00(89.39)$ & $100.00(89.39)$ & $86.11(76.20)$ & 0.00 \\
\hline Mean & $14.16(17.92)$ & $33.88(36.41)$ & $50.55(46.77)$ & & \\
\hline$C D_{0.05}$ & \multicolumn{5}{|c|}{ Isolate $(I \mathrm{~s})=1.97 ;$ Interval $(I)=1.08 ;$ Isolate $(I \mathrm{~s}) \times$ Interval $(I)=3.41$} \\
\hline
\end{tabular}


was recorded as least effective treatment with $53.77 \%$ disease control. Yuan et al. (2017) investigated the role of endophytic fungi on Verticillium wilt, and CEF-818 (P. simplicissimum), CEF-714 (Leptosphaeria sp.), CEF-642 (T. flavus.), and CEF193 (Acremonium sp.) isolated from cotton roots were used to assess their effects against cotton wilt disease. In the sick nursery, compared to controls (with disease incidence of $33.8 \%$ and disease index of 31), CEF-818, CEF-193, CEF-714, and CEF-642 provided a protection effect of $69.5,69.2,54.6$, and $45.7 \%$, respectively. These results implied that application of endophytes not only just deferred but also minimized wilt symptoms on cotton.

\section{Establishment and root colonization assay of selected root endophytes \\ Root colonization assay}

The potential of the 6 most efficient root endophytes after their identification with phylogenetic gene sequencing were assessed for their colonization in endosphere, and rhizosphere of apple, and population was monitored after 1st and 3rd week after treatment with culture suspension. The data embedded in Table 5 for colonization behavior of endophytic fungi revealed that total endophytic and rhizospheric count was significantly greater in case of fungal endophytic suspension-treated seedlings in comparison to untreated control. The total population count of endophytic and rhizospheric microbes increased progressively as culturable population was recorded more on the third week in comparison to the 1 st week of inoculation.

Colonization of fungal endophytes in general results in the emission of hydrolyze of plant cells which restrict the growth and evolution fungi; consequently, fragments of endophytes, performing as elicitors, are originated by hydrolyzation. The elicitors for instance, lipopolysaccharides, polysaccharides, and glycoprotein stimulate plant defense, and secondary metabolites, which further obstruct the attack of pathogen efficiently. The potential of fungal root endophytes to colonize endosphere and rhizosphere of apple was evaluated after the 1st and 3rd week of treatment with culture suspension. The data depicted in Table 5 revealed that total endophytic and rhizospheric population was significantly superior in case of fungal endophytic suspension-treated seedlings in comparison to untreated control.

The total population count of endophytic and rhizospheric microbes increased sharply as culturable population was recorded more after the 3rd week in comparison to the 1st week of inoculation. The maximum fungal endophytic count $\left(8.33 \times 10^{1} \mathrm{cfu} / \mathrm{g}\right.$ root $)$ on PDA medium after 21 days was recorded in roots of seedlings, which were treated with $C$. tabtim strain M8 suspension, followed by $F$. equiseti strain M1 $\left(7.67 \times 10^{1} \mathrm{cfu} / \mathrm{g}\right.$ root $)$. However, the minimum count $\left(2.33 \times 10^{1} \mathrm{cfu} / \mathrm{g}\right.$ root $)$ was recorded with roots of un-inoculated seedlings. Likewise in rhizosphere, the maximal microbial population $\left(17.67 \times 10^{3} \mathrm{cfu} / \mathrm{g}\right.$ soil $)$ was observed in rhizosphere soil, whereby seedlings were contended with C. tabtim strain M8 suspension, followed by $F$. equiseti strain M1 $\left(14.67 \times 10^{1} \mathrm{cfu} / \mathrm{g}\right.$ root $)$. However, the minimum count $\left(8.67 \times 10^{3} \mathrm{cfu} / \mathrm{g}\right.$ soil $)$ was noticed in untreated control. After termination of experiment, isolation was further taken from each treated root, and soil samples, and interestingly population of inoculated samples were found in dominance over other fungal microflora. Thus, suggested the colonization and endowment of injected strains in endo, and rhizosphere of apple seedlings.

\section{Microscopic elucidation of colonized and established root endophytes}

To investigate the ability of selected root endophytes to colonize, interact, and established in the interior environment of the host plants, treated apple root samples were taken, and processed with calcofluor white staining, followed by confocal microscopy. Confocal microscopic photographs of transverse sections of root samples

Table 5 Enumeration of endophytic and rhizospheric fungal population after seedling dip treatment of apple with endophytic suspension in pot conditions

\begin{tabular}{|c|c|c|c|c|}
\hline \multirow[t]{2}{*}{ Isolate } & \multicolumn{2}{|c|}{$\begin{array}{l}\text { Endophytic fungal population }\left(\times 10^{1} \mathrm{~g}^{-1} \text { roots }\right) \\
\text { after days }\end{array}$} & \multicolumn{2}{|c|}{$\begin{array}{l}\text { Rhizospheric fungal population }\left(\times 10^{3} \mathrm{~g}^{-1} \text { soil) }\right. \\
\text { after days }\end{array}$} \\
\hline & 7 & 21 & 7 & 21 \\
\hline Fusarium equiseti strain M1 & 5.33 & 7.67 & 13.33 & 14.67 \\
\hline Talaromyces aculeatus strain Ap & 4.67 & 6.33 & 11.33 & 12.67 \\
\hline Neocosmospora perseae strain G & 4.33 & 5.67 & 9.67 & 11.00 \\
\hline Aspergillus aculeatus strain C2 & 3.33 & 4.67 & 8.33 & 10.33 \\
\hline Crinipellis tabtim strain M8 & 6.67 & 8.33 & 15.00 & 17.67 \\
\hline Fusarium circinatum strain $\mathrm{K} 3$ & 3.33 & 5.67 & 10.67 & 12.33 \\
\hline Control & 1.67 & 2.33 & 6.33 & 8.67 \\
\hline $\mathrm{CD}_{0.05}$ & \multicolumn{2}{|c|}{$\begin{array}{l}\text { Isolate }(I \mathrm{~s})=0.76 ; \text { Interval }(I)=0.40 \\
\text { Isolate }(I \mathrm{~S}) \times \text { Interval }(I)=\mathrm{NS}\end{array}$} & \multicolumn{2}{|c|}{$\begin{array}{l}\text { Isolate }(I \mathrm{~s})=0.95 ; \text { Interval }(I)=0.51 \\
\text { Isolate }(I \mathrm{I}) \times \text { Interval }(I)=\mathrm{NS}\end{array}$} \\
\hline
\end{tabular}


inhabited and colonized by various fungal root endophytes varied to a larger extent, and are presented in Fig. 4. The results demonstrated that each fungal root endophyte was able to colonize apple roots, whereas root sections from untreated plants showed negligible fungal growth within the root sections. Observations pertinent to transverse sections of roots revealed extensive root colonization by endophytes under intercellular spaces, and the outer cortex. Analysis of most promising fungal root endophytes within apple root sections using CLSM revealed a significant superior
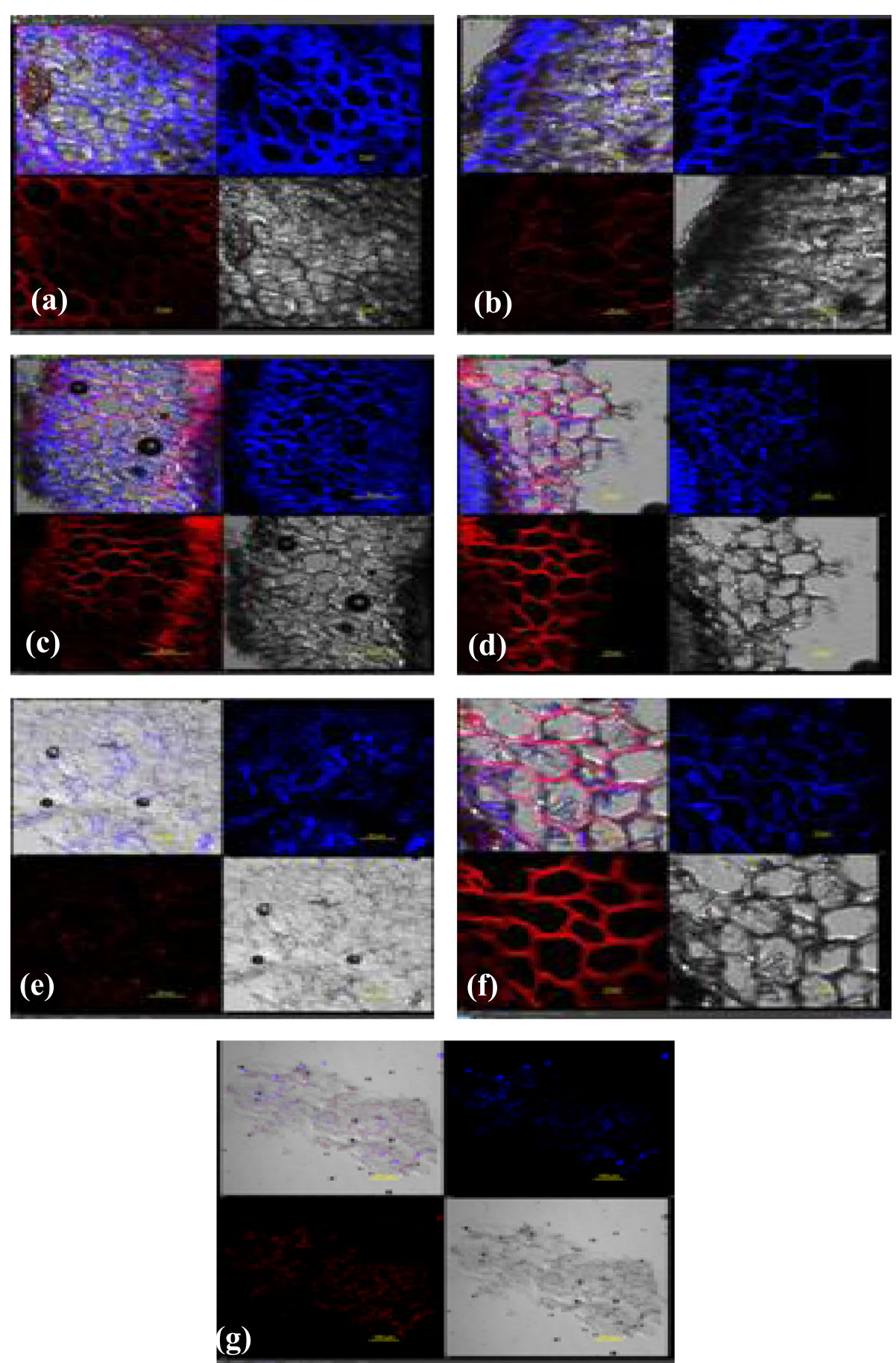

Fig. 4 Microscopic elucidation of colonized and established fungal root endophytes [a Fusarium equiseti strain M1, b Talaromyces aculeatus strain Ap, c Neocosmospora perseae strain G, d Aspergillus aculeatus strain C2, e Crinipellis tabtim strain M8, $\mathbf{f}$ Fusarium circinatum strain K3, and $\mathbf{g}$ control] by confocal laser scanning microscopy (CLSM) 
colonization in comparison to untreated control. Nearly all root sections from every treatment were ascertained to be colonized by different fungal root endophytes.

Root sections inoculated with buffer only showed negligible or no observable colonization. The root colonization events performed by representative fungal root endophytes are summarized in Fig. 4. Interestingly, the colonization configuration of different fungal root endophytes varied to a higher extent suggesting the distinct degrees of colonization. Root colonization is prominently marked by the scanty growth, and occasionally cells assimilate compact intracellular plugging of hyphae. The colonization constellation of different fungal root endophytes was more often observed in the intercellular parts of epidermis, and the outer cortex region in the transverse cross sections. In few root sections, endophytes appeared to be attached to the host cell wall or root epidermis. Similarly, Mousa et al. (2015) investigated the performance of WF4 (Phoma sp.) to colonize the finger millet roots by using confocal microscopy. Seedlings challenged with the buffer exhibited no detectable growth of pathogen interior the tissues. In comparison to buffer treated root, WF4 could effectively colonize the epidermis and sub-epidermal root tissue regions. Likewise, in the present research, calcofluor staining and confocal microscopy illustrations affirmed the endowment of fungal root endophytes to colonize root tissues efficiently. Ray et al. (2018) also visualized the confocal microscopic pictures pertaining to root cells of switch grass, signal grass, and crab grass colonized by endomycorrhizal fungus. Serendipita vermifera root persistence is generally pronounced by scanty or negligible growth augmentation between cells, and incidentally cells encompass compact intracellular lugging of fungal hyphae.

Colonization of plant parts by potential endophytic fungi may commence tremendous assistance to the host for instance plant growth promotion and defense against abiotic or biotic stresses (Maciá-Vicente et al. 2009). The present study emphasized to explore the interior plant values with unique root symbiotic microbes. The multifarious activity of these microbes suggested an alternative approach for management of soil-borne plant pathogens. In addition, the study also emphasizes the need for commercialization of these microbes as ready to use formulations prior to their deployment in the field.

\section{Conclusion}

The results showed that explorations of endophytes, particularly the root endophytes and acquaintance about its interactions are an expanded demesne of research. For the first time, a study highlights on the biocontrol and root colonization potential of fungal root endophytes against most destructive white root rot pathogen $(D$. necatrix) of apple. The bioformulation applications of these fungal endophytes, especially C. tabtim strain M8, F. equiseti strain M1, and T. aculeatus strain Ap could be used as an ecofriendly management of white root rot and other soil-borne plant pathogens in the future.

\section{Abbreviations}

ITS: Internal transcribed spacers; PDA: Potato dextrose agar; CTAB: Cetyl trimethyl ammonium bromide; BLAST: Basic Local Alignment Search Tool; NCBI: National Centre for Biotechnology Information; PDB: Potato dextrose broth; PDC: Per cent disease control; CLSM: Confocal laser scanning microscopy

\section{Acknowledgements}

The authors are thankful to the Directorate of Research University of Horticulture and Forestry Nauni, Solan (H.P.), for conferring the laboratory and glasshouse facilities as well as the Associate Director of Research Regional Horticultural Research and Training Station, Sharbo, Kinnaur (H.P.), for providing the field facilities for pursuing this study. Authors also gratefully acknowledge the Indian Institute of Technology, Mandi, Himachal Pradesh (India), for providing a scanning microscopy facility to carry out the root colonization studies.

\section{Authors' contributions}

JP, SKS, and AS conceived and designed the experiments. JP performed the experiments. SD, RS, and HR analyzed the data. JP, RS, and MK wrote the paper. JP, SV, and PRV contributed to the critical review and editing of the manuscript. All authors read and approved the final manuscript.

\section{Funding}

Not applicable

\section{Availability of data and materials}

The datasets used and/or analyzed during the current study are available from the corresponding author on reasonable request.

\section{Ethics approval and consent to participate}

Not applicable

Consent for publication

All authors consent to publish this article in the Egyptian Journal of Biological Pest Control.

\section{Competing interests}

The authors declare that they have no competing interests.

\section{Author details}

${ }^{1}$ Department of Plant Pathology, Dr. Y.S. Parmar University of Horticulture and Forestry, Nauni, Solan, Himachal Pradesh 173230, India. ${ }^{2}$ Department of Basic Sciences, Dr. Y.S. Parmar University of Horticulture and Forestry, Nauni, Solan, Himachal Pradesh 173230, India.

Received: 10 June 2020 Accepted: 31 August 2020

Published online: 10 September 2020

\footnotetext{
References

Agarwal GP, Hasija SK (1986) Microorganisms in Laboratory. Print House India Ltd. , Lucknow, p 155

Aharwal RP, Kumar S, Sandhu SS (2016) Endophytic mycoflora as a source of biotherapeutic compounds for disease treatment. J Appl Pharm Sci 6:242254

Amin R, Sarker BC, Adhikary SK, Sultana S, Zubair T (2013) Effect of some botanical extracts and cow's urine on Sclerotium rolfsii causal agent of foot and root rot of betel vine. Int J Eng Sci 2:77-82

Benhamou N, Kloepper JW, Tuzun S (1998) Induction of resistance against Fusarium wilt of tomato by combination of chitosan with an endophytic bacterial strain: ultrastructure and cytochemistry of the host response. Planta 204:153-168
} 
Coskuntuna A, Ozer N (2008) Biological control of onion basal rot disease using Trichoderma harzianum and induction of antifungal compounds in onion set following seed treatment. Crop Prot 27:330-336

Dutta D, Puzari KC, Gogoi R, Dutta P (2014) Endophytes exploitation as a tool in plant protection. Braz Arch Biol Technol 57:621-629

Fokkema NJ (1976) Antagonism between fungal saprophytes and pathogens on aerial plant surfaces. In: Dickinson CH, Preece TF (eds) Microbiology of aerial plant surfaces. Academic Press, London, pp 487-505

Gao F, Dai C, Liu X (2010) Mechanisms of fungal endophytes in plant protection against pathogens. Afr J Microbiol Res 4:1346-1351

Gomez KA, Gomez AA (1984) Statistical procedures for agricultural research, 2nd edn. Wiley, New York, p 680

Haiyan Li, Qing C, Zhang Y, Zhao Z (2005) Screening for endophytic fungi with anti-tumour and antifungal activities from chinese medicinal plants. World $J$ Microbiol Biotechnol 21:1515-1519

Hanafusa Y, Hirano Y, Watabe H, Hosake K, Ikezawa M, Shibahara T (2016) First isolation of Schizophyllum commune in a harbor seal (Phoca vitulina). Med Mycol 54:492-499

Ito SI, Nakamura N (1984) An outbreak of white root rot and its environmental conditions in the experimental arboretum. J Jap Soc Hort Sci 66:262-267

Kim HY, Choi GJ, Lee HB, Lee SW, Lim HK, Jang KS, Kim JC (2007) Some fungal endophytes from vegetable crops and their anti-oomycete activities against tomato late blight. Lett Appl Microbiol 44:332-337

Kulshrestha S, Seth CA, Sharma M, Sharma A, Mahajan R, Chauhan A (2014) Biology and control of Rosellinia necatrix causing white root rot disease: a review. J Pure Appl Microbiol 8:1803-1814

Maciá-Vicente JG, Jansson HB, Talbot NJ, Lopez-Llorca LV (2009) Real-time PCR quantification and live-cell imaging of endophytic colonization of barley (Hordeum vulgare) roots by Fusarium equiseti and Pochonia chlamydosporia. New Phytol 182:213-228

Mathur SB, Olga K (2003) Common laboratory seed health testing methods for detecting Fungi. DK-1871 Frederiksberg C, Copenhagen, p 425

Mousa WK, Schwan A, Davidson JP, Strange H, Liu T, Zhou Fl, Auzanneau RMN (2015) An endophytic fungus isolated from finger millet (Eleusine coracana) produces anti-fungal natural products. Front Microbiol 6:1-16

Murry MG, Thompson WF (1980) Rapid isolation of high molecular weight plant DNA. Nucleic Acids Res 8:4321-4325

Naraghi L, Heydari A, Rezaee S, Razavi M, Jahanifar H (2010) Study on antagonistic effects of Talaromyces flavus on Verticillium albo-atrum, the causal agent of potato wilt disease. Crop Prot 29:658-662

Ray P, Guo Y, Kolape J, Kraven KD (2018) Non-targeted colonization by the endomycorrhizal fungus, Serendipita vermifera, in three weeds typically cooccurring with Switchgrass. Front Plant Sci 8:1-9

Samson RA, Varga J, Frisvad JC (2011) Taxonomic studies on the genus Aspergillus. Stud Mycol 69:1-97

Santoyo G, Moreno-Hagelsieb G, Carmen Orozco-Mosqueda M, Glick BR (2016) Plant growth promoting bacterial endophytes. Microbiol Res 183 : 92-99

Sharma S, Roy S (2015) Isolation and Identification of a novel endophyte from a plant Amaranthus spinosus. Int J Curr Microbiol App Sci 4:785-798

Sharma SK, Gupta VK (1996) Management of root rot of apple through soil amendments with plant materials. Plant Dis Res 10:164-167

Sharma SK, Gupta VK (1997) Efficacy of carbendazim for the control of white root rot of apple. J Soil Biol Ecol 17:120-123

Sharma SK, Kishore DK, Pramanick (2005a) Effect of soil solarization on soil microflora and survival of Dematophora necatrix in temperate fruit nurseries. Acta Hortic 696:381-386

Sharma SK, Kishore DK, Pramanick $(2009,40)$ Apple white root rot - Dematophora necatrix (Hartig) Berl. Indian Agricultural Research Institute, Regional Station Amartara Cottage, Shimla, Technical Bulletin

Sharma SK, Sharma M, Gupta M (2005b) Role of bacterial antagonists in the management of white root rot in apple. Integrated plant disease management. In: Challenging problems in horticultural and forest pathology Solan, India, pp 39-46

Shentu XP, Liu WP, Zhan XH, Xu YP, Xu JF (2014) Transcriptome sequencing and gene expression analysis of Trichoderma brevicompactum under different culture conditions. PLoS One 9:e94203

Thomas P, Reddy KM (2013) Microscopic elucidation of abundant endophytic bacteria colonizing the cell wall-plasma membrane peri-space in the shoottip tissue of banana. AoB Plants 5:1-12
Thomas P, Upreti R (2014) Testing of bacterial endophytes from non-host sources as potential antagonistic agents against tomato wilt pathogen Ralstonia solanacearum. Adv Microbiol 4:656-666

Yuan Y, Feng H, Wang L, Li Z, Shi Y, Zhao L, Feng Z, Zhu H (2017) Potential of endophytic fungi isolated from cotton roots for biological control against Verticillium wlit disease. PLoS One 12:e0170557

Yurnaliza AINP, Esyanthi RR, Susanto A (2014) Antagonistic activity assessment of fungal endophytes from oil palm tissue against Ganoderma boninense Pat. Plant Pathol J 13:257-267

\section{Publisher's Note}

Springer Nature remains neutral with regard to jurisdictional claims in published maps and institutional affiliations.

\section{Submit your manuscript to a SpringerOpen ${ }^{\circ}$ journal and benefit from:}

- Convenient online submission

- Rigorous peer review

- Open access: articles freely available online

High visibility within the field

- Retaining the copyright to your article

Submit your next manuscript at $\boldsymbol{\sim}$ springeropen.com 